\title{
The relation between driving errors and executive functioning in intellectually able young novice drivers with autism
}

Citation for published version (APA):

Ross, V., Jongen, E. M. M., Brijs, K., Vanroelen, G., Beelen, C., Maltagliati, I., van Beers, M., Ruiter, R. A. C., Brijs, T., Alhajyaseen, W., Soliman, A., Wets, G., \& Vanvuchelen, M. (2019). The relation between driving errors and executive functioning in intellectually able young novice drivers with autism. Transportation Research Part F-Traffic Psychology and Behaviour, 63, 38-54. https://doi.org/10.1016/j.trf.2019.03.003

Document status and date:

Published: 01/05/2019

DOI:

10.1016/j.trf.2019.03.003

Document Version:

Publisher's PDF, also known as Version of record

\section{Document license:}

Taverne

Please check the document version of this publication:

- A submitted manuscript is the version of the article upon submission and before peer-review. There can be important differences between the submitted version and the official published version of record.

People interested in the research are advised to contact the author for the final version of the publication, or visit the DOI to the publisher's website.

- The final author version and the galley proof are versions of the publication after peer review.

- The final published version features the final layout of the paper including the volume, issue and page numbers.

Link to publication

\footnotetext{
General rights rights.

- You may freely distribute the URL identifying the publication in the public portal. please follow below link for the End User Agreement:

www.umlib.nl/taverne-license

Take down policy

If you believe that this document breaches copyright please contact us at:

repository@maastrichtuniversity.nl

providing details and we will investigate your claim.
}

Copyright and moral rights for the publications made accessible in the public portal are retained by the authors and/or other copyright owners and it is a condition of accessing publications that users recognise and abide by the legal requirements associated with these

- Users may download and print one copy of any publication from the public portal for the purpose of private study or research.

- You may not further distribute the material or use it for any profit-making activity or commercial gain

If the publication is distributed under the terms of Article $25 \mathrm{fa}$ of the Dutch Copyright Act, indicated by the "Taverne" license above, 


\title{
The relation between driving errors and executive functioning in intellectually able young novice drivers with autism
}

\author{
Veerle Ross ${ }^{\mathrm{a}, *}$, Ellen M.M. Jongen ${ }^{\mathrm{b}}$, Kris Brijs ${ }^{\mathrm{a}}$, Giovanni Vanroelen ${ }^{\mathrm{c}}$, Caroline Beelen ${ }^{\mathrm{d}}$, \\ Irene Maltagliati ${ }^{\mathrm{e}}$, Martijn van Beers ${ }^{\mathrm{f}}$, Robert A.C. Ruiter ${ }^{\mathrm{j}}$, Tom Brijs ${ }^{\mathrm{a}}$, Wael Alhajyaseen ${ }^{\mathrm{g}}$, \\ Abdrabo Soliman $^{\mathrm{h}}$, Geert Wets ${ }^{\mathrm{a}}$, Marleen Vanvuchelen ${ }^{\mathrm{i}}$ \\ ${ }^{a}$ Hasselt University, School for Transportation Sciences, Transportation Research Institute (IMOB), Agoralaan, 3590 Diepenbeek, Belgium \\ ${ }^{\mathrm{b}}$ Open University, Faculty of Psychology and Educational Sciences, Valkenburgerweg 177, Heerlen, the Netherlands \\ ${ }^{\mathrm{c}}$ Hasselt University, Faculty of Applied Engineering Sciences, Agoralaan, 3590 Diepenbeek, Belgium \\ ${ }^{\mathrm{d}}$ KU Leuven, Faculty of Psychology and Educational Sciences, Parenting and Special Education, Belgium \\ ${ }^{\mathrm{e}}$ University of Groningen, Faculty of Behavioural and Social Sciences, Grote Kruisstraat 2, 9712 TS Groningen, the Netherlands \\ ${ }^{\mathrm{f}}$ Maastricht University Medical Center+, NUTRIM School for Nutritionand Translational Research in Metabolism, Department of Respiratory Medicine, Maastricht, \\ the Netherlands \\ ${ }^{g}$ Qatar University, College of Engineering, Qatar Transportation and Traffic Safety Center, P.O. Box 2713, Doha, Qatar \\ ${ }^{\mathrm{h}}$ Qatar University, College of Art and Sciences, P.O. Box 2713, Doha, Qatar \\ ${ }^{\mathrm{i}}$ Hasselt University, Faculty of Medicine and Life Sciences, Rehabilitation Research Center (REVAL), Agoralaan, 3590 Diepenbeek, Belgium \\ ${ }^{\mathrm{j}}$ Maastricht University, Faculty of Psychology and Neuroscience, Universiteitssingel 40, 6229 ER Maastricht, the Netherlands
}

\section{A R T I C L E I N F O}

\section{Article history:}

Received 15 February 2018

Received in revised form 5 November 2018

Accepted 2 March 2019

Available online 3 April 2019

\section{Keywords:}

Autism spectrum disorder

Driving simulation

Young novice drivers

Driving errors

Road hazards

Executive functioning

\begin{abstract}
A B S T R A C T
Driving is a complex, goal-directed task. ASD can be related to impairments in executive functioning (EF), which may interfere with driving. This study aimed to investigate (1) if 16 young novice drivers with ASD exhibited a divergent performance on EF tests compared to 18 neurotypical peers, (2) if ASD participants exhibited a divergent driving performance compared to their neurotypical peers, and (3) if differences in driving performance would be related by the performance on the EF tasks. All participants completed a driving simulator scenario and computer-task battery. Driving error classification allowed the selection of several driving measures (e.g., collisions, speeding). Three EF tasks measuring working memory (WM), attention, and response inhibition were included. Results indicated lower WM and attention performance of the ASD participants compared to the control group, whereas response inhibition was similar across groups. Furthermore, the current study demonstrated that people with ASD can be considered as capable drivers once they have learned how to drive, that it is important to take different types of hazards into account, and that EF performance is related to driving performance. This relation may be different for drivers with and without ASD. Moreover, the relation may depend on the specific EFs and driving parameters under investigation. Future research could focus on the very early phases of driving education, and include additional driving and EF measures.
\end{abstract}

(c) 2019 Elsevier Ltd. All rights reserved.

\footnotetext{
* Corresponding author at: Hasselt University, School for Mobility Sciences, Transportation Research Institute (IMOB), Agoralaan, 3590 Diepenbeek, Belgium.

E-mail address: veerle.ross@uhasselt.be (V. Ross).
} 


\section{Introduction}

Driving is an important step towards gaining autonomy as it allows the development and maintenance of work-related and social contacts (Cox, Reeve, Cox, \& Cox, 2012). Yet, the ability to drive safely is hard to acquire, especially for persons on the autism spectrum. The official diagnosis of an autism spectrum disorder (ASD) refers to "a neurodevelopmental disorder characterized by impairments in social interaction and communication, as well as repetitive behaviors and restricted interests" (American Psychological Association, 2013). A recent study from the US compared adolescents with and without ASD from the Children's Hospital of Philadelphia healthcare network patient database. Although 83.5\% of the neurotypical adolescents acquired a driving license by the age of 21, only 1 in 3 of the ASD adolescents did so (Curry, Yerys, Huang, \& Metzger, 2018).

Driving comprises several subtasks running in parallel, between which one must be able to switch in a smooth manner (e.g., shifting gears, steering, changing lanes, and keeping traffic rules into account). Sudden changes in the traffic environment (e.g., traffic density, weather conditions) are additional difficulties. Hence, driving is a complex goal-directed task that places high demands on perceptual, cognitive, and motor processes (Monahan, Classen, \& Helsel, 2013; Ross et al., 2014, Ross, Jongen, Brijs, et al., 2015). Therefore, it is not surprising that driver errors contribute to 70-75\% of driver collisions, indicating that driver errors are directly related to traffic safety (Allahyari et al., 2008; Stanton \& Salmon, 2009).

\subsection{Executive functioning}

Executive functions (EFs), such as set shifting, working memory, and response inhibition, refer to a cluster of higher-order cognitive processes mediated by the prefrontal cortex, which enable an individual to perform goal-directed actions and problem solving (Rapport, Orban, Kofler, \& Friedman, 2013). The relation between EFs and driving ability has already been investigated in neurotypical young novice drivers as they constitute a risk group for crashes.

For one part, this increased accident risk has been explained by insufficient driving experience (McCartt, Shabanova, \& Leaf, 2003; Sagberg \& Bjørnskau, 2006). Another explanation involves the fact that the adolescent brain has not fully matured yet (Gogtay \& Thompson, 2010; Gogtay et al., 2004; Steinberg, 2005). Neuroscientific evidence shows that the brain areas providing behavioral 'drive', the limbic system, mature early. Meanwhile, the areas responsible for control over behavioral drive, the fronto-striatal connections, mature into young adulthood (Casey, Jones, \& Somerville, 2011; Stevens, Kiehl, Pearlson, \& Calhoun, 2007). Different effects of this maturation process can be postulated. First, this developmental imbalance can create an excessive amount of 'drive', which in turn may result in risky behavior (Steinberg, 2005). The effect of this imbalance is especially prominent in male drivers, who weigh the benefits of risk taking more heavily than the costs compared to female drivers (Gardner \& Steinberg, 2005). Second, many aspects of driving (e.g., vehicle control: Gugerty, 2011) only become automated over time with increasing driving experience. Since non-automated tasks require a larger investment of cognitive resources, novice drivers need to devote more of their already sparse resources to the driving task (Ross et al., 2014). One important driving ability is hazard avoidance, "the process of avoiding a collision with a hazard from initial searching for hazards through to the successful selection of an appropriate response" (Crundall \& Pradhan, 2016). It is possible to identify several sub processes in hazard avoidance, for instance, hazard searching, fixation, mitigation, reaction, and response. A full description of all processes goes beyond the scope of this article. We refer the reader to Crundall and Pradhan (2016) for a detailed definition and delineation of all the different sub processes. In the current study, we included hazards since responses towards them depend both on driving experience and cognitive resources, aspects that are both relevant for young novice drivers.

ASD is often accompanied by EF difficulties such as problem-solving, cognitive flexibility, WM, self-monitoring, and generating novel solutions when adjusting to unexpected changes (Chen et al., 2016; Hill, 2004; Hughes, Russell, \& Robbins, 1994; Pellicano, 2012; Turner, 1999). Thus, adolescents with ASD simultaneously fall into two potential risk categories: they belong to the novice driver population and show EF difficulties. Nevertheless, research on driving performance of novice drivers with ASD is still too scarce (e.g., Huang, Kao, Curry, \& Durbin, 2012; Ross, Jongen, Brijs, et al., 2015), and often does not relate driving performance to EF, or does not include hazards. A summary of the research in ASD that related driving performance to EF or included hazards is summarized below.

\subsection{Research on autism spectrum disorder, driving, and executive functioning}

Cox et al. (2016), studied a sample ranging from 15 to 23 years of age, and showed a different response to increased WM load in ASD compared to neurotypical controls. Increased WM demands resulted in decreased steering and braking in the ASD group, whereas it increased steering and braking in the control group, during a simulated drive. Classen, Monahan, and Hernandez (2013) linked increased driving errors (e.g., speed regulation, lane maintenance) to selective and divided attention in both pre-licensed and licensed adolescents with ASD. Furthermore, Daly, Nicholls, Patrick, Brinckman, and Schultheis (2014) speculated that driving errors might relate to EF difficulties. Via self-report, they found that licensed adults with ASD considered themselves as 'poor drivers', and also reported to commit more driving errors compared to non-ASD participants. Chee, Lee, Patomella, and Falkmer (2017) used a driving simulator, the Driving Behaviour Questionnaire (DBQ), and measures of cognitive and visual-motor ability. They found a worse performance in ASD participants, compared 
to a typically developing control group, with respect to some measures. Specifically, they reported more lapses (i.e., inability to focus and effectively allocate and sustain attention) during driving, more driving mistakes, and slower reactions in complex situations, during simulated driving. However, ASD participants did not show as much tailgating as the control group. Finally, some errors could be related to insufficient attentional capacity in the ASD group. Chee et al. (2017) investigated several driving measures (i.e., speed exceedances, collisions, pedestrians hits, centerline crossings, red light tickets, and tailgating). As for hazardous situations, Chee et al. (2017) only measured the ultimate outcome (i.e., collisions). However, measurement of reaction times to approaching hazards provides additional relevant information as slower reaction times lead to an increased collision risk (Bishop, Biasini, \& Stavrinos, 2017).

Some studies investigated hazard avoidance in particular and compared responses to social with responses to non-social hazards. Hazards can be defined as social in case of a clearly visible person, compared to non-social in case of an object such as a car. In non-social conditions, the hazard can involve a human element such as a driver in a car, but the human element should not be visible (Bishop et al., 2017; Sheppard, Ropar, Underwood, \& van Loon, 2010; Sheppard, Van Loon, Underwood, \& Ropar, 2017). For instance, Sheppard and colleagues used video clips and found atypical processing of road hazards. The latter study further specified that this was probably caused by slower attention orienting. Although in the first study ASD participants were found to respond more slowly to social hazards (Sheppard et al., 2010), the second study (Sheppard et al., 2017) did not find such a difference. One limitation of both studies was that they used videos instead of actual driving. A third study from Bishop et al. (2017) used driving simulation and found differences in hazard avoidance performance between yound adults with and without ASD that related to the social nature of hazards. Specifically, participants without ASD responded quicker to social hazards, whereas participants with ASD responded just as quick to social and non-social hazards (Bishop et al., 2017). Although these studies distinguished social and non-social hazards, none of them used the distinction previously proposed by Crundall and colleagues (Crundall et al., 2012; Crundall, Andrews, Van Loon, \& Chapman, 2010), i.e., behavioral prediction (BP) hazards (e.g., a parked car pulls out in front of the driver after a passenger has left the vehicle), environmental prediction (EP) hazards (e.g., two pedestrians are hidden by a bus shuttle and start to cross when the driver passes by), and dividing and focusing attention (DF) hazards (e.g., in a small curvy road, an approaching lorry comes from a small blind bend, pulls out to avoid crashing into a pedestrian, and occupies the driver's lane). One could hypothesize different performance of ASD drivers based on the respective category. For instance, due to difficulties with multitasking and mental flexibility (e.g., Rajendran et al., 2011; Van Eylen et al., 2011), one could expect more difficulties with DF hazards as these contain multiple potential hazards between which one must alternately switch attention.

\subsection{Objectives}

In sum, there are indications that EFs could play a role in the driving performance of young adults with ASD. Given the relation between driving errors and traffic safety, it is important to better understand driving errors in ASD, and their relation with underlying EF mechanisms. Moreover, special attention is given to road hazards.

This study aimed to replicate and extend previous research to answer the following three questions: (1) do ASD participants exhibit a divergent pattern of performance on EF tests related to driving, compared to their neurotypical peers? (2) do ASD participants exhibit a divergent pattern of driving performance compared to their neurotypical peers? and (3), are differences in driving performance related to performances on EF tasks?

\section{Methods}

The current paper expands on the proceeding paper that was presented at Road Safety and Simulation (RSS) 2017 (Ross et al., 2017). While the proceeding paper focused mainly on the response to hazards and working memory, the current analyses expanded the topic to driving errors in general, and to multiple EF measures (see below). This study was approved by the ethical committees of Hasselt University and the Catholic University of Leuven (reference number ML10787).

\subsection{Participants}

A total of 19 young novice drivers with ASD participated in the current experiment. The ASD participants were between 17 and 25 years old and had a maximum of 2 years driving experience. They were recruited via local advertisements at school and within university grounds in Flanders (the Dutch speaking part of Belgium). Advertisements were also distributed via mailing lists for university students with special needs. Diagnosis of participants with ASD was confirmed by a medical record indicating a diagnosis according to a multidisciplinary clinical consensus classification for ASD (Diagnostic and Statistical Manual of Mental Disorders (4th ed.; DSM-IV; American Psychiatric Association (APA), 1994; Diagnostic and Statistical Manual of Mental Disorders (4th ed., text rev.; DSM-IV-TR; APA, 2000). To exclude mental task-related incapacities, all participants had obtained at least 12 years of general education. The latter led to the exclusion of three participants with ASD. The final sample of drivers with ASD consisted of 16 participants ( 11 males; mean age $=20.00$ years, $S D=1.55$ ). The Social Responsiveness Scale for Adults (SRS-A), a self-report screening tool for autism symptoms (Constantino et al., 2003; Noens et al., 2012) was used to screen for symptoms related to ASD (mean SRS $=66.25$; $S D=15.75$ ). The control group of neurotypical participants consisted of 18 participants (10 males; mean age $=20.28$ years; $S D=1.87$ ) that were selected 
from a database $(n=54)$ from a previous study from Wang, Jongen, Brijs, Brijs, Ruiter, and Wets (2013). Wang et al. (2013) investigated visual search skills in young novice drivers with the same driving scenario as was used in the current study. The control group owned a (provisional) driving license and had a maximum of 1 year driving experience (Wang et al., 2013). There was no SRS data available for this group. The age distribution did not significantly differ between the two groups (Mann-Whitney $U=136.00, z=-0.28, p=.80$ ), and neither were there gender differences (Chi-Square $\chi^{2}=0.54, p=.53$ ). Finally, driving experience was queried by estimating how much kilometers participants drove on average per month (6point scale; $1:<50 \mathrm{~km}$ to 6 : $>2000 \mathrm{~km}$ ). The monthly driving experience did not significantly differ between both groups (Chi-Square $\chi^{2}=9.09, p=.06$; mean: ASD $=2.06$, control $=2.28$; category $2=$ between 50 and $150 \mathrm{~km}$ ).

All ASD participants signed an informed consent form before participation in the study. They received a gift coupon of 20 euros (22.43 dollars) for their participation.

\subsection{Procedure}

The ASD participants completed five tasks, in randomized order: (1) a driving task consisting of a 5 min warm-up drive (i.e., to get acquainted with the driving simulator; $5 \mathrm{~min}$ ), followed by the test drive $(20 \mathrm{~min})$; (2) the Stop Signal Task (20 min); (3) the WM task (10 min); (4) the UFOV (15 min); and finally, (5) a questionnaire on demographic data.

\subsubsection{Tasks}

2.2.1.1. Stop-signal paradigm. The stop-signal paradigm, measuring response inhibition, was derived from Jongen, Brijs, Komlos, Brijs, and Wets (2011). It included 2 practice sessions of 40 trials each and 1 experimental session of 96 trials. During each session a two-choice reaction time task was used. A stimulus (an ' $\mathrm{X}$ ' or an ' $\mathrm{O}$ ') was presented in the middle of a monitor screen and participants were required to press a button (left or right) in response to that stimulus. The first practice session aimed to determine the individual reaction time for each participant, which was used as a reference for the second practice and the experimental session.

In the first practice session, $1000 \mathrm{~ms}$ after the beginning of each trial, a fixation cross was presented for $500 \mathrm{~ms}$, followed by the stimulus for another $1000 \mathrm{~ms}$, which required a response between 150 and $1000 \mathrm{~ms}$ after onset. In both the second practice and the experimental session, the same two-choice reaction time was used, but on a randomly selected $25 \%$ of trials, an auditory stimulus $(1000 \mathrm{~Hz}, 70 \mathrm{~dB}, 100 \mathrm{~ms})$ was presented in addition to the visual primary-task stimulus. Presentation of this tone indicated that the subject needed to refrain from responding to the stimulus in that trial. Importantly, the time interval between the stimulus and the stop signal was initially set at $50 \mathrm{~ms}$ below participants' individual reaction time. Subsequently, the interval varied dynamically according to a staircase tracking algorithm, to converge on a stop-signal delay (SSD) at which the probability of stopping was 50\%. The SSD was increased by $50 \mathrm{~ms}$ if the response was successfully inhibited and decreased by $50 \mathrm{~ms}$ when it was not. The stop-signal reaction time (SSRT) represents the time participants took to inhibit their pre-programmed responses to the visual stimulus, after hearing the stop signal. This measure can be derived by subtracting the average SSD from the average reaction time. A higher score on the SSRT indicates lower response inhibition performance (Ross, Jongen, Brijs, et al., 2015; Ross, Jongen, Brijs, Brijs, \& Wets, 2016; Verbruggen \& Logan, 2008).

2.2.1.2. WM task. Three tasks were used to measure WM: the visuospatial span (i.e., measuring visuospatial WM), backward digit span and letter span (both measuring verbal WM; Ross, Jongen, Brijs, et al., 2015). These tasks were adapted from Houben, Wiers, and Jansen (2011) and Klingberg, Forssberg, and Westerberg (2002).

In the visuospatial span task, squares were presented on a computer screen on a $4 \times 4$ grid of which some sequentially turned blue. Participants had to reproduce the sequence they observed by clicking on the squares that turned blue in the correct order. In the backward digit span task, participants were presented with numbers appearing in sequences on the screen. They were asked to remember the sequence, and then click on the numbers presented in a grid in the reverse order to the initial sequence. Finally, in the letter span task, several letters were sequentially presented in a circle. Subsequently, one of the circles turned red, and participants were asked to enter the corresponding letter. All tasks started with a threeitem sequence; one item was added each time participants reproduced the sequence correctly, whereas after two incorrect answers the task stopped. In all three tasks, the number of items in the sequence correctly reproduced constituted the outcome measure. A higher level indicated higher WM performance (Ross, Jongen, Brijs, et al., 2015).

2.2.1.3. Useful Field of View test. The Useful Field of View (UFOV) test, measuring visual attention, has been used extensively in driving research, and predicts driving parameters (Clay et al., 2005; McManus, Cox, Vance, \& Stavrinos, 2015). It consisted of three subtests: visual processing speed, divided attention, and selective attention, respectively (Ball, Beard, Roenker, Miller, \& Griggs, 1988; Sekuler \& Ball, 1986). In the first subtest, a stimulus (a car or a truck) was presented at a central fixation point, and the task for the participants was to identify whether a car or a truck was shown. In the second subtest, the central stimulus was presented simultaneously with a peripheral one (a car); the identification of both the central and the peripheral one was required. The third test involved both stimuli again, and additionally included visual distractors collocated around the peripheral target. The stimuli were presented on a 19-inch monitor and participants responded using a computer mouse (Edwards et al., 2005; Jongen, Perrier, Vuurman, Ramaekers, \& Vermeeren, 2015). The scores on the three subtasks were expressed in milliseconds, and the total detection time was computed by summation of the three subtest results (Edwards et al., 2005). Higher reaction times indicate lower attentional capacities. 
2.2.1.4. Driving task. The STISIM M400 driving simulator (Systems of the Technology Interactive Simulator) was used. It is characterized by a fixed base and a medium level of fidelity, and consists of a force-feedback steering wheel, brake pedal, and accelerator. The simulation included vehicle dynamics, visual and auditory feedback and a performance measurement system that recorded data at $60 \mathrm{~Hz}$. Three LCD monitors were positioned around the visual field of the driver, displaying the virtual environment of the simulation. The screens had the following characteristics: size $=34 \times 27 \mathrm{in}$., resolution $=1024 \times 768$ pixels, distance from central monitor to participant $= \pm 105 \mathrm{~cm}$, visual field covered $=55^{\circ} \times 14^{\circ}$. The driving scenario resembled the Flemish road environment. The speedometer, side- and rear-view mirrors were also displayed on the monitors.

The $16 \mathrm{~km}$ driving scenario by Wang et al. (2013) was used, which included country, suburban, urban, as well as motorway road types, and 20 pre-programmed hazards.

Driver errors can be caused by different mechanisms, as described in error classifications. For instance, Stanton and Salmon (2009) identified five psychological mechanisms underlying driver errors; action (e.g., pressing the accelerator paddle instead of the brake), cognition and decision-making (e.g., misjudging the speed of an approaching vehicle), observation (e.g., failure to observe offside mirrors when changing lanes), information retrieval (e.g., misreading road signs), and violations (e.g., speeding). Keeping the characteristics of the current design into account (e.g., without including eye-tracking it can be difficult to distinguish errors in information retrieval), we selected several driving measures. We measured the frequency of collisions with the preprogrammed hazards but also with other traffic and/or objects in the surrounding and total number of stops at two yellow and two red lights. To measure speed, we calculated the average speed above and below the speed limit (i.e., driving too slowly can also be considered a driving error). Moreover, we calculated the percentage of the total distance driven above and below the speed limit, indicating the amount of driving at inappropriate speeds. For the latter, we used a tolerance level of $10 \%$ to exclude segments of speed control, including small fluctuations in speed, hereby only focusing on the amount of true low and excessive speed. Furthermore, the standard deviation of the lateral lane position (SDLP), or lane-keeping, was calculated. Data segments including lights, events, or curves were excluded for this calculation (Ross et al., 2015). Finally, the scenario included the above mentioned hazard types: BP, EP, and DF. The sequence in which these hazard types occurred was pseudo-randomized so that hazards of the same type did not occur in clusters. In our study, we included measures of hazard response. ${ }^{1}$ To this end, we selected two hazards from each of the three above-named categories, leaving a selection of six. Table 1 represents the specific hazards analyzed in the current study, their description and their precursors. Visual examples of these hazard types are represented in Fig. 1. First, the response to hazards was represented by the reaction time to hazards, which was calculated from hazard-onset to onset brake press. To account for accidental brake presses, considering the entire pedal range, only when the brake was pressed for $10 \%$, it was considered as an actual response (Reyes \& Lee, 2008; Boets, Ross, Van Belle, Vanroelen, \& Jongen, 2015). Brake reactions were counted as missing values when the $10 \%$ criteria was already reached at onset. Secondly, the time-to-collision was determined at the time of brake onset, which indicates the time it takes to collide with an object if the driver continued its path with the current speed. Thirdly, speed change on approach to the hazard was calculated. First, speed had to be interpolated because time sampling ensured that driving parameters were collected at constant time intervals, leading to distance intervals that were dependent on the driving speed. To avoid a negative correlation between speed and number of sampled data points, we transformed both time and distance sampling to preferred data points using interpolation (Ariën et al, In preparation). Second, speed was averaged in zones of $10 \mathrm{~m}$ for a $100 \mathrm{~m}$ zone before the hazard location. The speed in the $10-0 \mathrm{~m}$ zone was then subtracted from the $100-90 \mathrm{~m}$ zone to indicate the speed change. The brake reaction time and time-to-collision indicate the level of risk of the timing of the reaction (i.e., late reaction indicates more risk). The speed change indicates how abrupt the reaction was (i.e., higher levels indicating more abrupt response).

\subsubsection{Data analysis}

Statistical analysis of the data was conducted with IBM SPSS software version 20, by applying hierarchical regression. No outliers were identified or excluded from the analyses. For the purposes of interaction analyses, independent variables were standardized by transforming them into z-scores before they were entered into the analyses. All significance tests were twotailed.

We conducted two different analyses to answer the research questions. The first analysis aimed to examine whether diagnosis of ASD predicted performance on each EF task. First, we executed correlations between the EF measures per group. We conducted three hierarchical regressions; one for each EF task (SSRT, WM, and UFOV) as dependent variable. Group (ASD or control) was the independent variable and was added in the model using the Enter method.

The second analysis examined predictors of the selected driving parameters. First, we executed correlations per group. Second, we performed separate hierarchical regression analyses, one for each driving measure. In each analysis, using the Enter method, group (2 levels: control, ASD) was entered in the first block to investigate the differences in driving performance. In the second block, gender, driving experience, performance on the separate EF tasks, and their interaction with group (i.e., to determine whether the influence of the predictor varied per group), were entered in the model. To increase

\footnotetext{
1 We have chosen for the overall term hazard response, and broke this down into different components such as reaction time. Note that Crundall and Pradhan (2016) make a distinction between hazard reaction "Any behavioral outcome from identifying a hazard" and hazard response "A subsection of hazard reactions composed of deliberate actions (e.g., intentional braking)". The term 'response' has been chosen to be consistent throughout the article, but technically, we are not able to firmly distinguish between deliberate (response) and undeliberate (reaction) actions.
} 
Table 1

Behavioral prediction (BP), environmental prediction (EP), and dividing and focusing (DF) hazards.

\begin{tabular}{lll}
\hline Type of hazard & Description & Precursor \\
\hline BP hazards & $\begin{array}{l}\text { A car stops in front of the driver in the opposite lane because a child and } \\
\text { dog are slowly crossing the street. The child and dog do not use the zebra } \\
\text { crossing } \\
\text { Two pedestrians exit a parked car on the right side and in front of the } \\
\text { driver; afterwards the car pulls out into the road (see Fig. 1) }\end{array}$ & The pedestrian that left the vehicle \\
& $\begin{array}{l}\text { Two children are approaching to cross the street on the zebra crossing but } \\
\text { they are temporally hidden by trees. No traffic lights are present (see Fig. 1) } \\
\text { Two children suddenly step out into the road from behind a parked bus } \\
\text { while there is a zebra-crossing 5 m away next to the bus stop }\end{array}$ & A 30-zone limit and a school sign \\
& $\begin{array}{l}\text { On small curvy roads, an approaching truck appears from behind a small } \\
\text { blind bend. It pulls out to avoid crashing into a pedestrian and thereby } \\
\text { occupies the driver's lane } \\
\text { One pedestrian with a dog crosses the zebra lines and another pedestrian } \\
\text { appears to want to cross too (see Fig. 1) }\end{array}$ & A pedestrian sign \\
& & A pedestrian sign
\end{tabular}
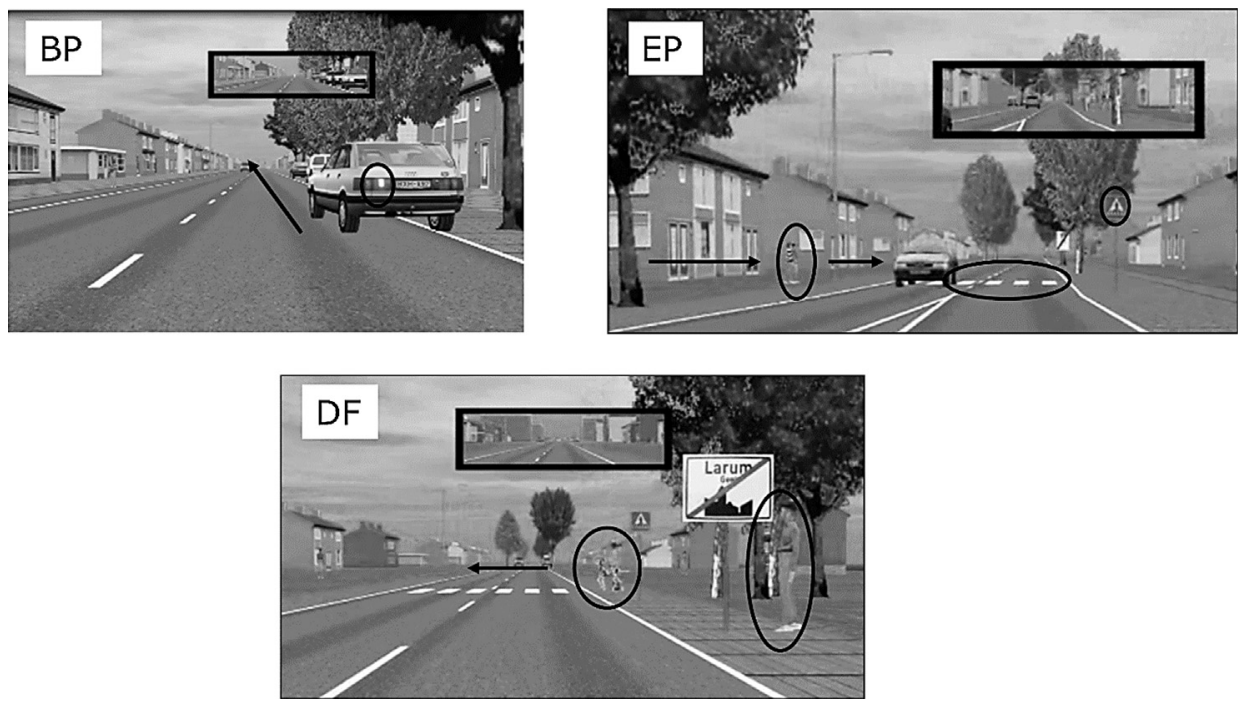

Fig. 1. Visual examples of the hazard types. This figure illustrates one example for each type of hazard. BP: behavioral prediction, EP: environmental prediction, and DF: dividing and focusing hazards.

statistical power, Forward selection was used in the second block (i.e., only predictors and interactions contributing significantly to the model were included; the used significance value was alpha $=0.05$ ). If the Forward selection produced a model with significant interaction effects, the model was repeated using Enter to include the respective main effects in order to perform the follow-up analyses. Finally, we executed simple slope tests to examine the significance of the interaction at two values of the moderator, indicating low $(-1 \mathrm{SD})$ and high values $(+1 \mathrm{SD})$. Note that low value of group indicates 'ASD' and high value 'control'. For gender, low value indicates 'male' and high value 'female'.

\section{Results}

The descriptive statistics of the two groups are shown in Table 2. Table 3 displays the correlations between the EF measures per group.

Participants with ASD appeared to perform worse on the SSRT than the control group, explaining $4.6 \%$ of variance in SSRT. Nevertheless, group did not significantly predict SSRT performance, $F(1,32)=1.55, \beta=-0.22, p=.22$. Meanwhile, group did significantly predict performance on the WM and UFOV tasks. Group explained $15.2 \%$ of the variance in the WM task, $F(1,32)$ $=5.72, \beta=0.39, p=.02$; and $25.5 \%$ of variance in the UFOV, $F(1,32)=10.94, \beta=-0.51, p<.01$. The ASD group scored significantly more poorly on the UFOV and WM tasks compared to the control group.

See Table 4 for the final models. Visualizations of significant interaction effects are included in Figs. 2 and 3. None of the included predictors made a significant contribution towards explaining any variance in collisions and stops at traffic lights. 
Table 2

Descriptive statistics.

\begin{tabular}{|c|c|c|c|c|c|c|c|c|}
\hline & \multicolumn{5}{|c|}{ Control group } & \multicolumn{3}{|c|}{ ASD group } \\
\hline & Mean & $S D$ & Min & $\operatorname{Max}$ & Mean & $S D$ & Min & $\operatorname{Max}$ \\
\hline SSRT & 214.70 & 31.81 & 144.79 & 280.56 & 229.63 & 38.17 & 170.61 & 312.04 \\
\hline WM & 21.89 & 3.63 & 17 & 28 & 18.75 & 4.03 & 13 & 26 \\
\hline UFOV & 74.34 & 23.33 & 50.10 & 143.10 & 120.08 & 53.28 & 50.10 & 226.60 \\
\hline Collisions & 1.06 & 1.11 & 0 & 4 & 1.88 & 1.89 & 0 & 6 \\
\hline Stops & 1.94 & 1.39 & 0 & 4 & 1.44 & 1.09 & 0 & 3 \\
\hline SDLP & 0.20 & 0.04 & 0.13 & 0.28 & 0.22 & 0.10 & 0.11 & 0.44 \\
\hline Mean speed over limit & 3.62 & 3.55 & 0.66 & 14.26 & 4.62 & 4.55 & 0.00 & 14.26 \\
\hline Length over limit & 7.22 & 9.7 & 0.00 & 36.50 & 10.96 & 12.92 & 0.00 & 35.25 \\
\hline Mean speed under limit & -6.98 & 3.15 & -14.23 & -2.93 & -6.22 & 3.32 & -12.66 & -2.01 \\
\hline Length under limit & 20.12 & 15.03 & 1.94 & 53.06 & 17.43 & 14.79 & 0 & 49.85 \\
\hline Brake reaction time BP & 1.72 & 0.49 & 1.05 & 2.83 & 1.65 & 0.44 & 1.19 & 2.90 \\
\hline Time to collision BP & 1.66 & 0.33 & 1.00 & 2.17 & 1.67 & 0.45 & 0.53 & 2.30 \\
\hline Speed change BP & 12.23 & 5.33 & 1.70 & 20.26 & 16.92 & 5.49 & 8.32 & 25.70 \\
\hline Brake reaction time EP & 2.48 & 1.02 & 1.28 & 5.09 & 1.93 & 0.63 & 0.79 & 2.78 \\
\hline Time to collision EP & 2.44 & 0.89 & 0.79 & 3.86 & 2.46 & 0.73 & 1.65 & 3.95 \\
\hline Speed change EP & 23.24 & 7.04 & 7.09 & 32.78 & 23.04 & 5.57 & 12.75 & 34.77 \\
\hline Brake reaction time DF & 1.49 & 0.31 & 0.80 & 1.98 & 1.71 & 0.38 & 1.11 & 2.40 \\
\hline Time to collision DF & 3.16 & 0.37 & 2.48 & 3.74 & 2.92 & 0.36 & 2.35 & 3.76 \\
\hline Speed change DF & 32.23 & 6.16 & 21.14 & 41.37 & 29.40 & 6.89 & 19.50 & 42.95 \\
\hline
\end{tabular}

Note: SSRT: stop-signal reaction time; UFOV: useful field of view; WM: working memory; SDLP: standard deviation of the lateral lane position; BP: behavioral prediction, EP: environmental prediction; DF: dividing and focusing.

Table 3

Correlations between the different executive functioning measures, per group.

\begin{tabular}{|c|c|c|c|c|c|c|c|}
\hline & & \multicolumn{3}{|c|}{ Control } & \multicolumn{3}{|l|}{ ASD } \\
\hline & & SSRT & WM & UFOV & SSRT & WM & UFOV \\
\hline \multirow[t]{2}{*}{ SSRT } & $r$ & 1 & -0.10 & 0.01 & 1 & -0.05 & 0.05 \\
\hline & $p$ & & 0.69 & 0.99 & & 0.85 & 0.84 \\
\hline \multirow[t]{2}{*}{ WM } & $r$ & -0.10 & 1 & -0.17 & -0.05 & 1 & $-0.77^{* *}$ \\
\hline & $p$ & 0.69 & & 0.51 & 0.85 & & $<0.001$ \\
\hline \multirow[t]{2}{*}{ UFOV } & $r$ & 0.01 & -0.17 & 1 & 0.05 & $-0.77^{* *}$ & 1 \\
\hline & $p$ & 0.99 & 0.51 & & 0.84 & $<0.001$ & \\
\hline
\end{tabular}

SSRT: stop-signal reaction time; UFOV: useful field of view; WM: working memory.

** Correlation is significant at the 0.01 level (2-tailed).

For SDLP, no effect of group was found. However, participants with a worse performance on the UFOV showed a larger SDLP, indicating more lane-keeping variability.

There was no significant main effect of group for the mean speed driven over the speed limit. Looking at the length of the distance that participants drove over the speed limit, there was a significant interaction of group*UFOV. With a worse UFOV performance, participants with ASD drove a shorter length over the speed limit, compared to the control group. Meanwhile, the effect was reversed with a better UFOV performance, where ASD participants drove a longer length over the speed limit than the control group. The simple slope analysis confirmed these findings, in case of worse UFOV performance (gradient: $4.54, t=2.68, p=.01$ ) and in case of better UFOV performance (gradient: $-5.92, t=-3.2, p<.01$ ). For the mean speed driven below the limit, no significant effects were found. Considering the length driven under the speed limit, there was no significant main effect of group. However, there were two interactions, group*WM and group*UFOV. In case of a better WM performance, the driven length below the speed limit was similar between groups (simple slope: gradient: $8.38, t=-0.02$, $p=.99$ ). However, with low WM performance (i.e., higher score), especially the control group drove a longer length below the speed limit (value; gradient: $-0.06, t=2.34, p=.03$ ), compared to the ASD group. Regarding the interaction with UFOV, there was no group difference in case of worse UFOV performance (i.e., high UFOV value; gradient: $-1.59, t=-0.45, p=.66$ ). However, in case of better UFOV performance (i.e., low UFOV value; gradient: 9.91, $t=2.56, p=.02$ ) the ASD group drove a shorter length under the speed limit, compared to the control group.

For the reaction time to BP hazards, there was no significant effect of group. A main effect for SSRT did indicate that participants with better response inhibition (i.e., lower score) reacted sooner to BP hazards, indicating less risk. Going to time to collision for BP hazards, again, there was no effect of group. However, significant main effects from response inhibition and WM indicated that participants with better response inhibition and WM performance showed a higher time to collision value, again indicating less risk. For speed change, a significant interaction of group*WM indicated that with a better WM performance, there was no difference in performance between ASD drivers and the control group (high score; gradient: $-1.33, t=-0.96, p=.34)$. With a lower WM performance, the ASD group reacted more abruptly to BP hazards, compared to the control group (low score; gradient: $-4.59, t=-3.74, p=.001$ ). 
Table 4

Regression Models for Part 2.

\begin{tabular}{|c|c|c|c|c|c|c|}
\hline Model & $R^{2}$ & $F$ & $p$ & Predictor & $\beta$ & $p$ \\
\hline Collisions & 0.07 & 2.44 & 0.13 & Group & -0.27 & 0.13 \\
\hline Stops at traffic lights & 0.04 & 1.37 & 0.25 & Group & 0.20 & 0.25 \\
\hline SDLP & 0.27 & 5.83 & $<0.01$ & $\begin{array}{l}\text { Group } \\
\text { UFOV }\end{array}$ & $\begin{array}{l}0.09 \\
0.55\end{array}$ & $\begin{array}{l}0.60 \\
<0.01\end{array}$ \\
\hline Mean speed above limit & 0.30 & 4.19 & 0.01 & $\begin{array}{l}\text { Group } \\
\text { SSRT } \\
\text { Group*SSRT }\end{array}$ & $\begin{array}{l}0.03 \\
0.33 \\
-0.29\end{array}$ & $\begin{array}{l}0.90 \\
0.18 \\
0.17\end{array}$ \\
\hline Length speed above limit & 0.31 & 4.40 & 0.01 & $\begin{array}{l}\text { Group } \\
\text { UFOV } \\
\text { Group*UFOV }\end{array}$ & $\begin{array}{l}0.06 \\
-0.29 \\
0.44\end{array}$ & $\begin{array}{l}0.72 \\
0.10 \\
0.01\end{array}$ \\
\hline Mean speed below limit & 0.01 & 0.47 & 0.50 & Group & -0.12 & 0.50 \\
\hline Length speed below limit & 0.37 & 3.22 & 0.02 & $\begin{array}{l}\text { Group } \\
\text { UFOV } \\
\text { WM } \\
\text { Group*UFOV } \\
\text { Group*WM }\end{array}$ & $\begin{array}{l}0.28 \\
0.12 \\
0.55 \\
-0.37 \\
0.34\end{array}$ & $\begin{array}{l}0.12 \\
0.53 \\
0.01 \\
0.04 \\
0.07\end{array}$ \\
\hline Brake reaction time $\mathrm{BP}$ & 0.15 & 2.65 & 0.09 & $\begin{array}{l}\text { Group } \\
\text { SSRT }\end{array}$ & $\begin{array}{l}0.30 \\
0.43\end{array}$ & $\begin{array}{l}0.13 \\
0.03\end{array}$ \\
\hline Time to collision BP & 0.43 & 7.52 & $<0.01$ & $\begin{array}{l}\text { Group } \\
\text { SSRT } \\
\text { WM }\end{array}$ & $\begin{array}{l}-0.11 \\
-0.97 \\
0.82\end{array}$ & $\begin{array}{l}0.51 \\
<0.001 \\
<0.001\end{array}$ \\
\hline Speed change BP & 0.29 & 4.14 & 0.01 & $\begin{array}{l}\text { Group } \\
\text { WM } \\
\text { Group*WM }\end{array}$ & $\begin{array}{l}-0.46 \\
-0.06 \\
0.33\end{array}$ & $\begin{array}{l}0.01 \\
0.76 \\
0.05\end{array}$ \\
\hline Brake reaction time EP & 0.27 & 5.91 & $<0.01$ & $\begin{array}{l}\text { Group } \\
\text { Experience }\end{array}$ & $\begin{array}{l}0.35 \\
-0.42\end{array}$ & $\begin{array}{l}0.03 \\
0.01\end{array}$ \\
\hline Time to collision EP & 0.00 & $<0.01$ & 0.95 & Group & -0.01 & 0.95 \\
\hline Speed change EP & 0.18 & 2.25 & 0.10 & $\begin{array}{l}\text { Group } \\
\text { Gender } \\
\text { Group*Gender }\end{array}$ & $\begin{array}{l}-0.01 \\
0.16 \\
0.39\end{array}$ & $\begin{array}{l}0.97 \\
0.36 \\
0.03\end{array}$ \\
\hline Brake reaction time DF & 0.33 & 7.49 & $<0.01$ & $\begin{array}{l}\text { Group } \\
\text { Gender }\end{array}$ & $\begin{array}{l}-0.37 \\
0.49\end{array}$ & $\begin{array}{l}0.02 \\
<0.01\end{array}$ \\
\hline Time to collision DF & 0.36 & 4.07 & 0.01 & $\begin{array}{l}\text { Group } \\
\text { Gender } \\
\text { SSRT } \\
\text { Group*SSRT }\end{array}$ & $\begin{array}{l}0.50 \\
-0.38 \\
0.20 \\
0.47\end{array}$ & $\begin{array}{l}0.02 \\
0.02 \\
0.42 \\
0.03\end{array}$ \\
\hline Speed change DF & 0.34 & 3.70 & 0.02 & $\begin{array}{l}\text { Group } \\
\text { Gender } \\
\text { UFOV } \\
\text { Group*UFOV }\end{array}$ & $\begin{array}{l}0.28 \\
-0.39 \\
-0.03 \\
0.35\end{array}$ & $\begin{array}{l}0.11 \\
0.02 \\
0.87 \\
0.03\end{array}$ \\
\hline
\end{tabular}

Note: SSRT: stop-signal reaction time; UFOV: useful field of view; WM: working memory; SDLP: standard deviation of the lateral lane position; BP: behavioral prediction, EP: environmental prediction; DF: dividing and focusing.

Second, EP hazards are discussed. For the reaction time to EP hazards, a significant main effect of group again indicated a faster performance for the ASD group, indicating less risk. Moreover, a main effect of experience also indicated a quicker reaction to EP hazards for participants with more driving experience. Turning to the time to collision to EP hazards, no significant effects were found. Finally, for speed change towards EP hazards, a significant effect of group*gender indicated that in the case of females, the ASD participants were less abrupt in approaching EP hazards, compared to the control group. However, this was reversed in case of male ASD participants: they reacted more abruptly compared to the control group. However, considering the slope analysis, this effect was non-significant in case of females (gradient: $2.09, t=1.93, p=.17$ ), with only a trend towards significance for males (gradient: $-2.89, t=-1.94, p=.06$ ).

Third, DF hazards are discussed. For the reaction time to DF hazards, a significant main effect of group showed a later reaction time in the ASD group, indicating more risk. A main effect of gender indicated that in both groups, male drivers reacted sooner to the DF hazards, compared to female drivers. Considering time to collision to DF hazards, a significant interaction of group*SSRT indicated a similar performance between the groups in case of better response inhibition (i.e., low score; gradient: $-0.04, t=-0.45, p=.66$ ). In case of worse response inhibition (i.e., high score; gradient: $0.42, t=2.71$, $p=.01$ ), the ASD group showed a smaller time to collision value to DF hazards, indicating more risk, compared to the control group who actually performed better with worse response inhibition. Similar to reaction time, a significant effect of gender 

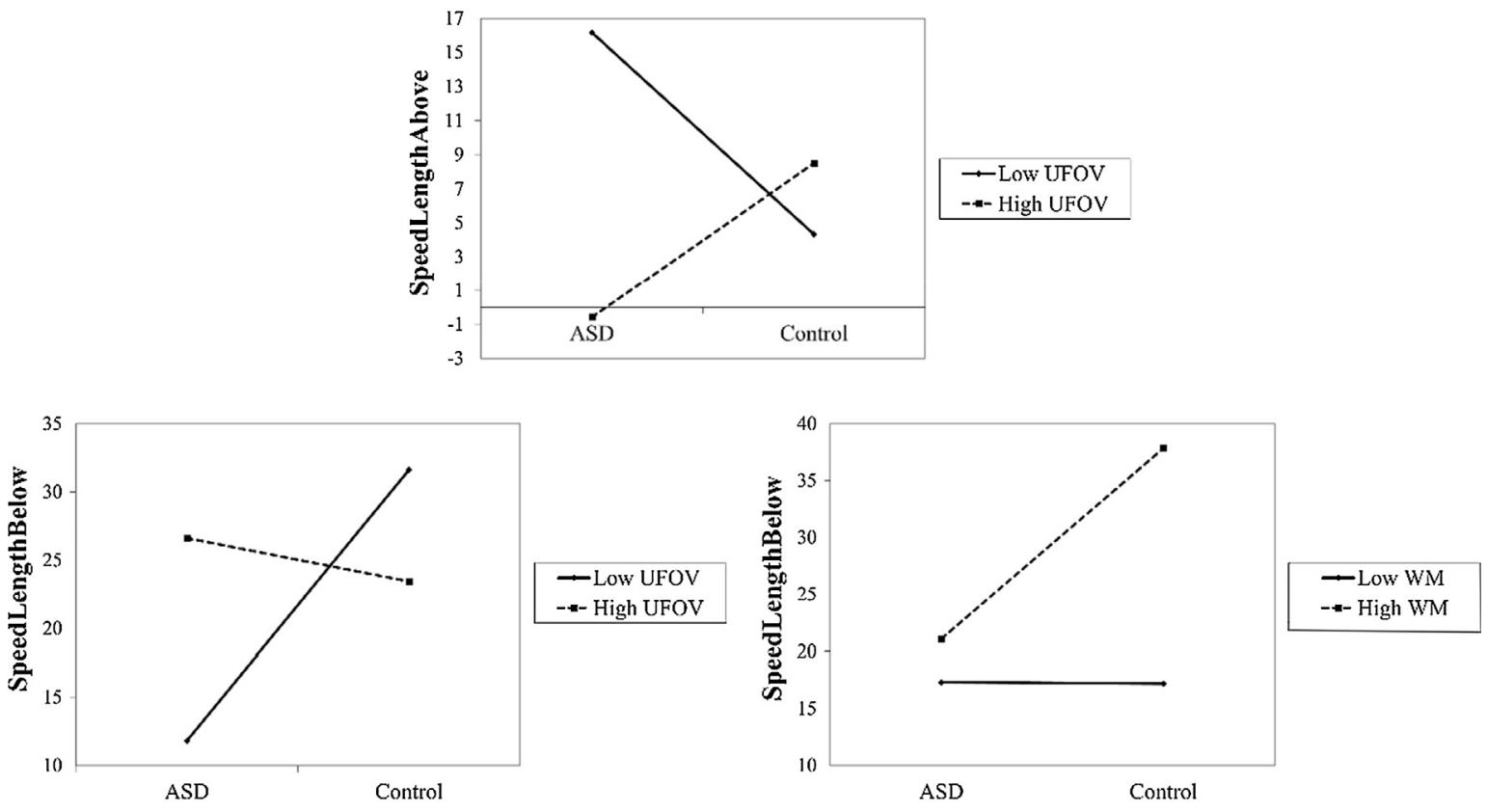

Fig. 2. Interaction visualizations; top: Length of the distance driven above the speed limit, interaction Group*UFOV; bottom left: Length of the distance driven below the speed limit, interaction Group*UFOV; bottom right: Length of the distance driven below the speed limit, interaction Group*WM. SSRT: stop-signal reaction time; UFOV: useful field of view; WM: working memory.
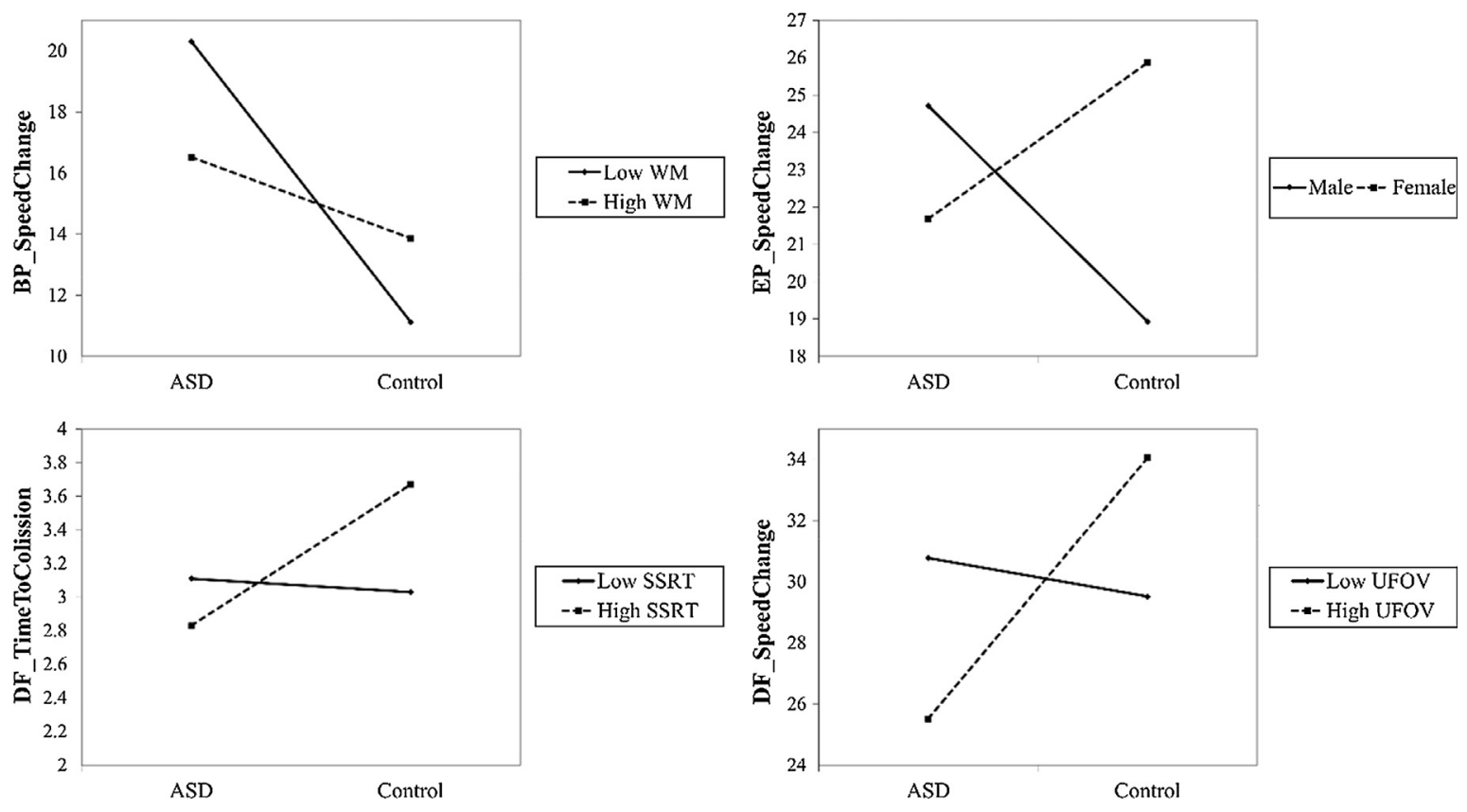

Fig. 3. Interaction visualizations; from left-to-right starting in the top left corner: Speed change Behavioral Prediction hazards, interaction Group*WM; Speed change Environmental Prediction hazards, interaction Group*Gender; Time to collision Dividing and Focusing hazards, interaction Group*Response inhibition; Speed change Dividing and Focusing hazards, interaction Group*UFOV. SSRT: stop-signal reaction time; UFOV: useful field of view; WM: working memory.

indicated that male drivers in both groups displayed higher time to collision values to DF hazards, indicating less risk. Considering the speed change to DF hazards, there was a significant group*UFOV interaction. In case of better UFOV performance (i.e., low score; gradient: $-0.63, t=-0.40, p=.70$ ), the performance between both groups was similar. However, in case of worse UFOV performance (i.e., high score; gradient: $4.27, t=-2.89, p<.01$ ), the ASD group reacted less abruptly to the DF 
Table 5

Summary of found effects.

\begin{tabular}{|c|c|c|c|c|c|}
\hline Variable & $\begin{array}{l}\text { Group } \\
\text { effect? }\end{array}$ & $\begin{array}{l}\text { Predictor } \\
\text { effect? }\end{array}$ & Relation EF/driving? & $\begin{array}{l}\text { Group*predictor } \\
\text { effect? }\end{array}$ & Relation interaction/driving? \\
\hline Collisions & $\mathrm{X}$ & $\mathrm{X}$ & 1 & $\mathrm{X}$ & 1 \\
\hline Stops at traffic lights & $\mathrm{X}$ & $\mathrm{X}$ & 1 & $\mathrm{X}$ & l \\
\hline SDLP & $\mathrm{X}$ & UFOV & Better UFOV $\rightarrow$ smaller SDLP & $\mathrm{X}$ & l \\
\hline $\begin{array}{l}\text { Mean speed above } \\
\text { limit }\end{array}$ & $\mathrm{X}$ & $\mathrm{X}$ & 1 & $\mathrm{X}$ & l \\
\hline $\begin{array}{l}\text { Length speed above } \\
\text { limit }\end{array}$ & $\mathrm{X}$ & $\mathrm{X}$ & 1 & Group*UFOV & $\begin{array}{l}\text { - Worse UFOV } \rightarrow \text { less speeding } \\
\text { in ASD } \\
\text { - Better UFOV } \rightarrow \text { more speeding } \\
\text { in ASD }\end{array}$ \\
\hline $\begin{array}{l}\text { Mean speed below } \\
\quad \text { limit }\end{array}$ & $\mathrm{X}$ & $\mathrm{X}$ & 1 & $\mathrm{X}$ & 1 \\
\hline \multirow[t]{2}{*}{$\begin{array}{l}\text { Length speed below } \\
\quad \text { limit }\end{array}$} & $\mathrm{X}$ & /I & /I & Group*WM & $\begin{array}{l}\text { - Worse } \mathrm{WM} \rightarrow \text { longer distance } \\
\text { too slow in control }\end{array}$ \\
\hline & & & & Group*UFOV & $\begin{array}{l}\text { - Better UFOV } \rightarrow \text { shorter dis- } \\
\text { tance too slow in ASD }\end{array}$ \\
\hline $\begin{array}{l}\text { Brake reaction time } \\
\quad \text { BP }\end{array}$ & $\mathrm{X}$ & SSRT & $\begin{array}{l}\text { Better SSRT } \rightarrow \text { shorter reaction } \\
\text { time }\end{array}$ & $\mathrm{X}$ & 1 \\
\hline \multirow[t]{2}{*}{ Time to collision BP } & $\mathrm{X}$ & SSRT & $\begin{array}{l}\text { Better SSRT } \rightarrow \text { longer time to } \\
\text { collision }\end{array}$ & $\mathrm{X}$ & 1 \\
\hline & & WM & $\begin{array}{l}\text { Better WM } \rightarrow \text { longer time to } \\
\text { collision }\end{array}$ & & \\
\hline Speed change BP & /I & $\mathrm{X}$ & 1 & Group*WM & - Worse WM $\rightarrow$ ASD more abrupt \\
\hline $\begin{array}{l}\text { Brake reaction time } \\
\quad \text { EP }\end{array}$ & ASD faster & Experience & $\begin{array}{l}\text { More experience } \rightarrow \text { shorter } \\
\text { reaction time }\end{array}$ & $\mathrm{X}$ & 1 \\
\hline Time to collision EP & $\mathrm{X}$ & $\mathrm{X}$ & 1 & $\mathrm{X}$ & 1 \\
\hline Speed change EP & $\mathrm{X}$ & $\mathrm{X}$ & l & Group*Gender & $\begin{array}{l}\text { - Female ASD } \rightarrow \text { less abrupt- } \\
\text { Males ASD } \rightarrow \text { more abrupt }\end{array}$ \\
\hline $\begin{array}{l}\text { Brake reaction time } \\
\quad \text { DF }\end{array}$ & $\begin{array}{l}\text { ASD } \\
\text { slower }\end{array}$ & Gender & Males $\rightarrow$ shorter reaction time & $\mathrm{X}$ & 1 \\
\hline Time to collision DF & /l & Gender & Males $\rightarrow$ smaller time to collision & Group*SSRT & $\begin{array}{l}\text { - Worse SSRT } \rightarrow \text { shorter time to } \\
\text { collision in ASD }\end{array}$ \\
\hline Speed change DF & $\mathrm{X}$ & Gender & Males $\rightarrow$ more abrupt & Group*UFOV & $\begin{array}{l}\text { - Worse UFOV } \rightarrow \text { ASD group less } \\
\text { abrupt and control more abrupt }\end{array}$ \\
\hline
\end{tabular}

Note: SSRT: stop-signal reaction time; UFOV: useful field of view; WM: working memory; SDLP: standard deviation of the lateral lane position. BP: behavioral prediction, EP: environmental prediction; DF: dividing and focusing; X: no effect. In case of a significant interaction effect, it is not allowed to interpret the main effects, this is indicated by $/ /$.

hazards, compared to the control group. Finally, a main effect of gender indicated that males reacted more abruptly to DF hazards compared to females, as indicated by higher speed change values.

Table 5 contains a summary of the found effects. Moreover, it contains a classification of the nature of the relations between $\mathrm{EF}$ and driving.

\section{Discussion}

The aim of this study was to investigate the relation between driving errors and EFs in young novice drivers with ASD. To this aim, we examined whether adolescents with ASD would show a divergent driving performance and response to hazards compared to neurotypical adolescents, and whether these differences would relate to differences in EFs.

\subsection{Group differences on the executive functioning tasks}

The control group performed better on the WM task and UFOV, compared to the ASD group. But we found no significant group differences on the SSRT. This resembles previous literature showing that people with ASD do not always perform worse than neurotypical controls on EF tasks. For instance, evidence for significantly differing SSRT results between ASD and neurotypical participants comes from Geurts, Verté, Oosterlaan, Roeyers, and Sergeant (2004), Verte, Geurts, Roeyers, Oosterlaan, and Sergeant (2005), Sinzig, Morsch, Bruning, Schmidt, and Lehmkuhl (2008), Chan et al. (2009), and Xiao et al. (2012). Evidence indicating that the groups do not significantly differ, comes from Solomon et al. (2009), and Johnston, Madden, Bramham, and Russell (2011). The inconsistency may depend on how constructs are measured. Parsons and Carlew (2016) found differences in response inhibition based on the type of task. They did not find differences on a paper-and-pen and a computer task, but did find worse response inhibition performance in ASD on a Virtual Classroom Bimodal Stroop task. Interestingly, the results of the current study indicate a better performance of the control group on the UFOV. This is relevant in light of Classen et al. (2013), who did not find any differences in UFOV performance between 
pre-licensed persons with ASD and the control group. The finding that the ASD group performed worse on the UFOV is relevant as UFOV training has been shown to generalize to multiple driving parameters, such as number of at-fault crashes (Ball, Edwards, Ross, \& McGwin, 2010) and risk of driving cessation (Edwards, Delahunt, \& Mahncke, 2009).

\subsection{Group differences in general driving performance and the relation to executive functioning}

The current study did not find any group differences with respect to collisions, stops at traffic lights, and SDLP, in contrast to previous studies. For instance, in the study by Classen et al. (2013), ASD individuals committed more errors than control participants regarding speed regulation, lane maintenance, the frequency of yellow and red light-running, signaling, and adjustment to unexpected events. Daly et al. (2014) examined past behaviors of drivers: ASD participants reported more speeding tickets and red light and stop-sign running compared to the control group. However, the former studies were not comparable to the current one, as they included pre-licensed drivers and self-report measures. In the driving simulator study by Cox et al. (2016), the control group showed much less collisions, swerving and lane changes than the ASD group, although speed control was comparable. The latter is in contrast with our own findings. Finally, we found some differences in speed control that related to EF, which will be discussed in the following paragraph. These differences may be caused due to several reasons. First, Cox et al. (2016) recruited participants from the age of 15. In our study, we recruited from the age of 17. Therefore, age could be a confounder since the former study included a younger sample. Second, we are not sure whether the driving experience from both studies was comparable. To the best of our knowledge, driving experience was not entered in the analyses by Cox et al. (2016). Moreover, while Cox et al. (2016) used a cut-off score of T-score > 60 on the SRS-parent report, we did not include such a cut-off (see limitations). Importantly, while both studies included driving simulation, the software, scenarios, measures, and methods to calculate these measures were different. Considering the above, a direct comparison of both studies may prove to be difficult. More research including comparative samples and designs are necessary to draw any firm conclusions about the differences that were found.

We found no relations between collisions, stops at lights, and SDLP on the one hand, and response inhibition or WM on the other hand. This is not in line with research on neurotypical young novice drivers (e.g., Mäntylä, Karlsson, \& Marklund, 2009; Ross, Jongen, Brijs, et al., 2015). We did find that better lane-keeping performance related to better UFOV performance in both groups. The UFOV is aimed at measuring processing speed and central vision, divided attention, and selective attention, but other functions are involved in the task execution as well (e.g., attention, EF, processing speed, acuity, etc.). Because the UFOV task involves this wide range of functions, it probably relates well with various everyday functions (Woutersen et al., 2017). Indeed, lane-keeping can be considered as a task requiring several visual-motor, but also cognitive, functions as one continuously has to keep a steady lane, while paying attention to the constantly changing driving environment.

The finding that better EF performance relates to better driving performance (i.e., a positive relation) is in line with theories postulating that, with the maturation in the brain of adolescents and young adults, cognitive enhancement leads to more and better self-control over behavior (e.g., Lambert, Simons-Morton, Cain, Weisz, \& Cox, 2014; Steinberg, 2008; Ross, Jongen, Brijs, et al., 2015; Ross et al., 2016). However, the relations between driving and EF in the current study were not always positive, but sometimes negative (i.e., when better EF performance relates to worse driving performance). This was also found in research on neurotypical young novice drivers. For instance, some studies have found that WM relates to more risky driving behavior (Ross, Jongen, Brijs, et al., 2015; Starkey \& Isler, 2016). To illustrate, Ross, Jongen, Brijs, et al. (2015) found that higher visuospatial WM performance related to more yellow-light running and a shorter minimal following distance to a leading vehicle in an urban environment. As possible explanations, they mentioned: (1) maybe the young adults with low WM capacity actually compensate for this lack in abilities by adopting safer driving behavior, balancing their capabilities with a larger safety margin (e.g., a larger following distance); (2) better WM performance has already been related to higher levels of sensation seeking, possibly these people enjoy to take risks; (3) there may be a relation to better processing speed, if people with higher capacities are better able to process information, they may also be better in reacting to more difficult driving situations, so that the so-called risk-taking would not involve actual risk (Ross, Jongen, Brijs, et al., 2015). The found results are discussed below in light of these possible explanations.

The above mentioned contradiction was clearly reflected in the measures associated with speed. We found that participants with ASD and worse UFOV performance drove a shorter distance under the speed limit than those with better UFOV performance. This would be counterintuitive if one expects better EF performance to be related to better driving performance. However, it is quite possible that ASD drivers with lower UFOV performance would lower their speed to enlarge their safety margin because of their limited capacity to detect and process relevant information. It is also possible that ASD drivers with higher UFOV performance do not perceive the speeding as dangerous or maybe even like the sensation of speeding, similar to previous findings in neurotypical young drivers (Ross, Jongen, Brijs, et al., 2015). However, the latter would contradict the rule-boundedness nature of people with ASD (Ross, Jongen, Vanvuchelen, et al., 2015), considering that speeding can be considered as a typical violation error (Ross, Jongen, Brijs, Brijs, \& Wets, 2016). Given that the mean speed driven above the speed limit is not that high (i.e., $4.62 \mathrm{~km} / \mathrm{h}$ ), the former would be more likely. Relations between speeding and response inhibition were not found, although other research did indicate a relation between violations and response inhibition (e.g., speeding increased in the presence of peer passengers, only in young drivers with low response inhibition, Ross et al., 2016; for a review, see Walshe et al., 2017). Referring back to the length of the distance driven below the speed limit, EF performance (i.e., WM and UFOV) related to driving performance. WM was especially important for the control group, where participants drove too slowly in case of worse performance, possibly indicating compensatory effects. For the ASD 
participants, better UFOV performance was related to faster driving, which could be related to an increased inclination to speed.

\subsection{Group differences in driving performance related to road hazards and the relation to executive functioning}

We found that different hazard types contribute to different responses towards them. First, for BP hazards, the reaction time and time to collision at the moment of the reaction were similar across groups. This aligns with the recent hazard avoidance study from Bishop et al. (2017), who did not find a difference between the control and the ASD group in the reaction time to social hazards during a simulated drive. Speed change to BP hazards did show group differences, which related to WM performance. The ASD participants with a lower WM performance reacted more abruptly to BP hazards, which may increase the chance for rear-end collisions in that group. Moreover, a better WM related to a longer time to collision and better response inhibition related both to shorter reaction times and a longer time to collision. This coincides with research in neurotypical young adults where response inhibition related to a better reaction to road hazards. However, to the best of our knowledge, this was the first time that WM was related to a better reaction to hazards (e.g., Hatfield, Williamson, Kehoe, \& Prabhakharan, 2017; Ross et al., 2017; for a review: see Walshe et al., 2017).

Second, the ASD group responded faster than the control group to EP hazards. People with ASD are believed to lack contextual sensitivity. According to the 'context blindness' hypothesis, ASD is characterized by a reduced spontaneous use of context. This could lead to deficiencies in the ability to use contextual information in predicting subsequent events (Vermeulen, 2009, 2015). This is exactly what they need to do in case of hazard response, where the development of the hazard has to be predicted based on the context. Still, in case of EP hazards, people with ASD outperformed the control group to EP hazards, an effect that was not found for BP hazards. This difference could have been caused by the nature of the context. For BP hazards, you have to 'derive' what will happen from behavior, such as deducing that a car is going to merge into traffic following a blinking direction indicator. That stimulus seems more implicit than being able to predict that someone might cross over based on a traffic sign before a pedestrian crossing. The link between the traffic sign and the pedestrian crossing is much more direct and explicit, compared to the link between a blinking direction indicator and merging into traffic (the driver merely indicates that he wants to perform a maneuver, he/she could also wait until you passed). Expressed in 'context terms': a traffic sign for crossover is an explicit context, the direction indicator is less explicit. Traffic signs are more explicit predictors of what can happen compared to 'behavior' because the meaning of behavior is more 'open' for interpretation compared to a traffic sign (Vermeulen, 2009). Moving on to speed change, this measure indicated a different effect for male and female ASD drivers, with females being less abrupt compared to males. A recent study already indicated differences between young males and females with ASD (7-18 years old) with respect to EF and adaptive behavior. Females showed larger EF problems than males and markedly worse adaptive daily living skills (White et al., 2017). A recent meta-analysis, however, indicates that dependent on the measure, females with ASD outperform males with ASD on, for instance, cognitive flexibility (Hull, Mandy, \& Petrides, 2017). In the current study, speed change to EP hazards was the only measure where we found a significant interaction between group and gender and we did not find EF differences, indicating a comparable performance between males and females with ASD. Finally, it was found that more experienced drivers reacted faster to EP hazards. Crundall et al. (2010) already mentioned that probably EP hazards are most likely to discriminate between novice and experienced drivers.

Third, as hypothesized, the performance of ASD drivers was worse compared to the control group in case of DF hazards, as shown by a slower reaction time. Furthermore, for those ASD participants with worse response inhibition, we found a shorter time to collision at the time of reaction. In research with neurotypical young drivers, improved response inhibition was already related to an improved response towards hazards, as shown in the brake reaction to hazards, (Ross et al., 2015). Finally, there was also an effect for speed change, and this related to UFOV. With worse UFOV, the ASD group reacted less abruptly compared to the control group. Possibly, the ASD group compensated for the lack in UFOV capabilities, while the control group did not, leading to an abrupt speed change in the latter group. In support of the compensatory strategy by the ASD group, the ASD participants with worse UFOV performance also showed less speeding behavior. The UFOV has already been related with driving performance, mainly in elderly drivers where it also related to hazard avoidance, and recently also in young drivers (McManus et al., 2015; Woutersen et al., 2017). Possibly, this measure relates especially to DF hazards because these hazards require attention to be switched between different possible hazard sources, which resembles UFOV subtest 3 measuring divided attention. In subtest 3, a peripheral stimulus is presented together with a central stimulus. The participant has to identify the peripheral stimulus, in addition to identifying the central stimulus (Woutersen et al., 2017). The UFOV was developed for elderly drivers, and similar to previous research with young adults, we encountered ceiling effects for subtest 1 and 2. Possibly, young adults need different cut-off scores for the UFOV, maybe combined with additional subtests, increasing task difficulty (McManus et al., 2015). Nonetheless, the UFOV showed several significant results in the current study, providing proof for the usefulness of the UFOV for ASD drivers. Finally, there was a general main effect of gender for DF hazards. Females across groups reacted slower, as indicated by reaction time and time to collision, but also less abruptly, compared to males. This coincides with the study from Ross et al. (2015) investigating neurotypical young drivers that found a slower total braking reaction time for females, compared to males. However, they did not distinguish between different hazard types, nor did they include time to collision or speed change. 


\subsection{Summary and future directions}

The current study found group differences in driving performance, although the ASD group did not always underperform in comparison to the control group and could be considered as quite capable drivers. Nevertheless, difficulties in learning how to driver were previously reported (e.g., Cox et al., 2012; Ross, Jongen, Vanvuchelen, et al., 2015). Future studies could focus more on driver education in ASD. In support, Patrick et al. (2018) compared driving performance of young adults with and without ASD, and found that differences mainly existed in the earlier phases of driving education. Furthermore, several relations between $\mathrm{EF}$ and driving performance were found. The nature of these relations depended on the type of driving measure and the type of EF, with sometimes better EF performance relating to better driving performance, and sometimes the other way around. This coincides with research in neurotypical young novice drivers where better EF performance was sometimes related to less (e.g., better verbal WM related to smaller SDLP) and sometimes to better (e.g., better visuospatial WM related to smaller following distance in the city center) driving performance (e.g., Ross, Jongen, Brijs, et al., 2015; for a review: see Walshe et al., 2017). Walshe et al. (2017) reported in their review that the divergence in found relations between EF and driving may depend on the multitude of used EF and driving measures (e.g., self-report, computer based, simulated, etc.). Additionally, in the current study, more relations between EF and driving were found for the ASD group, and mainly for WM and UFOV. Although speculative, this may depend on the lower WM and UFOV performance of the ASD group in the current study, making their driving performance more dependent on EF performance. Further research is called for to determine whether these effects can be replicated or extended.

Nonetheless, this study is one of the first driving simulator studies including multiple driving measures that not only indicated that high functioning young adults with ASD can be quite capable drivers, but also relate specific driving measures to computerized measures of $\mathrm{EF}$.

\section{Implications}

The current results imply that high functioning young adults with ASD can be considered as quite capable drivers once they learn how to drive. However, future studies could focus on dividing and focusing hazards, and possibly include them in ASD driver training programs. One important way to perform training is a driving simulator. The scant research that exists indeed suggests merits of using driving simulators to train driving in people with ASD (e.g., Cox et al., 2017; Wade et al., 2017). To illustrate, the research group from Wade and colleagues assembled an adaptive driving simulator system for assessment and training purposes, and already published a pilot study where they related visual attention to simulated driving performance. More specifically, in one study, they found more turning-related driving errors in an ASD young driver sample, compared to a neurotypical control group. In a second study, they found that simulated driving performance improved using both performance-based feedback and combined performance- and gaze-sensitive feedback (Wade et al., 2017). Relevant to the current study, the pilot study from Cox et al. (2017) indicated the potential usefulness for driving simulation training to increase driving performance, as well as EF performance, by translating three EF tasks (i.e., dual-tasking, response inhibition, and working memory) to a simulated driving environment. However, similar to conclusions made by Ross, Jongen, Brijs, et al. (2015) for neurotypical young drivers, it is important to first tease apart the specific relations between EF and driving, since a better EF performance is sometimes related to worse (or risky) driving instead of better driving performance.

\section{Limitations}

First, the sample size limited the statistical power and generalizability of this study, although the sample size of the current study is fairly equal to sample sizes in other comparable studies (e.g., Cox et al., 2016; Classen et al., 2013; Reimer et al., 2013). A larger sample size would have made it easier to obtain significant results, and would have given a more reliable estimation of effect sizes. Furthermore, a larger sample size would have allowed a full test of the model, instead of using the Forward method, possibly allowing additional significant predictors.

Second, there may have been a selection bias in the current study as it included intellectually able participants who at least passed their theoretical driving exam (i.e., preliminary license) or passed their practical driving exam (i.e., full license). This approach was used to reduce the chance that findings would be based on intellectual functioning differences. Therefore, results may only be generalized to a very specific part of the ASD population; those with a higher intellectual ability. Nevertheless, this group also experiences challenges to societal participation (e.g., getting an education, finding a job, building social relationships, etc.). In this group, driving can facilitate societal inclusion by allowing independent transportation.

Third, all participants in the ASD group had undergone a battery of widely used and validated diagnostic tests that were carried out by a multidisciplinary team. However, for most of the participants the diagnosis tests were carried out during childhood. Hence, we did not rate the actual remaining severity of ASD. If we consider our SRS self-report data, seven participants with a confirmed ASD diagnosis fell below the cut-off score for indications of ASD, which could have reduced performance differences between our ASD and control group. Nevertheless, group differences were still found in the current study. Moreover, considering the fact that ASD is related to EF difficulties, one would expect that participants with a potentially false ASD diagnosis would also show better EF performance compared to the remainder of the ASD group. A correlation analyses between ASD diagnosis (yes, no) and the three EF measures did not contribute any significant correlations, 
supporting their inclusion in the ASD group. However, to be sure that there is no confounding present in the ASD diagnosis, and to possibly identify additional group differences, future studies should include ASD participants with a more recent diagnosis.

Fourth, caution needs to be exercised when interpreting possible differences in response to different hazard types. The analyses only included two events for each hazard type. The reason for the limited selection comes from an in-depth investigation of the responses to each separate hazard. We discovered that not all hazards were suitable for analyses. For instance, some hazards were located at the intersection of two speed limit zones (e.g., from $70 \mathrm{~km} / \mathrm{h}$ to $50 \mathrm{~km} / \mathrm{h}$ ), making it difficult to determine whether a brake reaction was caused by the hazard, or the transition to another speed zone. Eye-tracking measures would have been beneficial in this respect, for instance, in case participants were looking at the hazard, instead of the sign. Due to the lack of eye-tracking, we opted to only include hazards where the driver responses could be clearly linked to the hazard situation. Follow-up studies including more events per hazard type should be executed.

Fifth, the simulated driving scenario did not include the same levels of workload and distraction as in actual driving, which might affect driving performance. A study by Reimer et al. (2013) indeed found that young males with and without ASD paid less attention to the overall driving environment when they were distracted by a mobile phone. In particular males with ASD paid less attention to traffic and had an increased heart rate, possibly indicating stress and anxiety. Indeed, Ross et al. (2018) used the Driving Attitude Scale Parent-Report (DAS-PR) that was developed to provide an indication of apprehensive driving. The response of the parents indicated possible driving apprehension in novice drivers with ASD that improved after following driving simulation training, albeit not up to the level of the neurotypical novice drivers at baseline. Therefore, the current study might overestimate the driving performance of young novice drivers with ASD. Furthermore, the current study could by no means capture the entire range of driving measures and errors. The driver error taxonomy by Stanton and Salmon (2009) includes five error categories: action errors, cognitive and decision making errors, observation errors, information retrieval errors, and violations. For instance, one could include measures of information retrieval (e.g., misread road sign; Stanton \& Salmon, 2009), which draws highly on WM and therefore might be impaired in ASD.

Finally, executive functioning is a broad construct, and the tests that were included in the current study are not the only ones to measure EF. For example, the $N$-back task, matrix monitoring task, plus-minus task (Mäntylä et al., 2009), numberletter task, Trail Making Test part B (Adrian, Postal, Moessinger, Rascle, \& Charles, 2011) and the Tower of London (Daigneault, Joly, \& Frigon, 2002) have all been used as EF measures in a driving context. The current study, however, aimed to provide a balance between including the full, broad range of tests measuring EFs, with the need to be concise, and to not administer more tests than absolutely necessary. Therefore, we based the selection of EF measures on driving research in other populations (e.g., young drivers: Ross et al., 2014, 2015; elderly drivers: Cuenen et al., 2016). Alternatively, we would have started from EF difficulties in ASD, and selected tasks based on these difficulties. Probably, we would have included cognitive inflexibility, which is experienced when an adjustment of behaviors is required (e.g., such as in task-switching tasks; Hoofs, Princen, Poljac, Stolk, \& Poljac, 2018). Not only is this ability very relevant due to the often reported implication in ASD, it is also very relevant for driving, in which one continuously has to switch between different sub-tasks (e.g., steering, braking, merging into traffic).

\section{Conclusion}

In conclusion, people with ASD showed worse EF performance than the neurotypical control group in the attention and WM domains, whereas their level of inhibition was comparable to that of the control group. The young novice drivers with ASD in our study were pretty skilled drivers. Dependent on the driving measure, the driving performance of young novice drivers with ASD was considered worse, equal, or even better, compared to the control group. Importantly, relations between $\mathrm{EF}$ and driving were found and, depending on the specific driving and EF measures, these relations could also be different for the control and ASD groups. To verify and refine the results of the current study, and provide additional avenues for developing driver training programs, future research should include early phases of driving education, and additional driving and EF measures.

\section{Funding}

This research was funded by the Belgian Marguerite-Marie Delacroix support fund (GV/B-226).

\section{Acknowledgments}

We would like to thank Weixin Wang for programming the scenario, and Dirk Roox and Marc Geraerts for the technical support. Moreover, we would like to thank Peter Vermeulen for his support and advice regarding the interpretation of results related to context blindness.

\section{Ethical approval}

This study was approved by the ethical committees of Hasselt University and the Catholic University of Leuven (reference number ML10787). 


\section{References}

Adrian, J., Postal, V., Moessinger, M., Rascle, N., \& Charles, A. (2011). Personality traits and executive functions related to on-road driving performance among older drivers. Accident Analysis \& Prevention, 43(5), 1652-1659.

Allahyari, T., Saraji, G. N., Adi, J., Hosseini, M., Iravani, M., Younesian, M., \& Kass, S. J. (2008). Cognitive failures, driving errors and driving accidents. International Journal of Occupational Safety and Ergonomics, 14(2), 149-158.

American Psychiatric Association (APA) (1994). Diagnostic and Statistical Manual of Mental Disorders (DSM IV) (4th ed). Washington, DC: APA.

American Psychiatric Association (APA) (2000). Diagnostic and Statistical Manual of Mental Disorders (DSM-IV-TR) (4th ed Text revision). Washington, DC: APA.

American Psychological Association (2013). Diagnostic and statistical manual of mental disorders. Washington, DC: Author.

Ariën, C., Vanroelen, G., Brijs, K., Jongen, E. M. M., Cornu, J., Ross, V., ..., Wets, G. (In preparation). Processing driving simulator data before statistical analysis by means of interpolation and an integral formula.

Ball, K. K., Beard, B. L., Roenker, D. L., Miller, R. L., \& Griggs, D. S. (1988). Age and visual search: Expanding the useful field of view. JOSA A, 5(12), $2210-2219$.

Ball, K., Edwards, J. D., Ross, L. A., \& McGwin, G. Jr, (2010). Cognitive training decreases motor vehicle collision involvement of older drivers. Journal of the American Geriatrics Society, 58(11), 2107-2113.

Bishop, H. J., Biasini, F. J., \& Stavrinos, D. (2017). Social and non-social hazard response in drivers with autism spectrum disorder. Journal of Autism and Developmental Disorders, 47(4), 905-917.

Boets, S., Ross, V., Van Belle, G., Vanroelen, G., \& Jongen, E. (2015) Effects of texting on driving behaviour of young drivers in urban traffic. Results of a simulator-based study. In Road safety and simulation conference, Orlando, USA (Oct. 6-8 2015).

Casey, B. J., Jones, R. M., \& Somerville, L. H. (2011). Braking and accelerating of the adolescent brain. Journal of Research on Adolescence, 21(1), 21-33.

Chan, A. S., Cheung, M. C., Han, Y. M., Sze, S. L., Leung, W. W., Man, H. S., \& To, C. Y. (2009). Executive function deficits and neural discordance in children with autism spectrum disorders. Clinical Neurophysiology, 120(6), 1107-1115.

Chee, D. Y. T., Lee, H. C. Y., Patomella, A. H., \& Falkmer, T. (2017). Investigating the driving performance of drivers with and without autism spectrum disorders under complex driving conditions. Disability and Rehabilitation, 1-8.

Chen, S. F., Chien, Y. L., Wu, C. T., Shang, C. Y., Wu, Y. Y., \& Gau, S. S. (2016). Deficits in executive functions among youths with autism spectrum disorders: An age-stratified analysis. Psychological Medicine, 46(8), 1625-1638.

Classen, S., Monahan, M., \& Hernandez, S. (2013). Indicators of simulated driving skills in adolescents with autism spectrum disorder. The Open Journal of Occupational Therapy, 1(4), 2.

Clay, O. J., Wadley, V. G., Edwards, J. D., Roth, D. L., Roenker, D. L., \& Ball, K. K. (2005). Cumulative meta-analysis of the relationship between useful field of view and driving performance in older adults: Current and future implications. Optometry and Vision Science, 82(8), 724-731.

Constantino, J. N., Davis, S. A., Todd, R. D., et al (2003). Validation of a brief quantitative measure of autistic traits: Comparison of the social responsiveness scale with the autism diagnostic interview-revised. Journal of Autism and Developmental Disorders, 33(4), 427-433.

Cox, D. J., Brown, T., Ross, V., Moncrief, M., Schmitt, R., Gaffney, G., \& Reeve, R. (2017). Can youth with autism spectrum disorder use virtual reality driving simulation training to evaluate and improve driving performance? An exploratory study. Journal of Autism and Developmental Disorders, 47(8), 2544-2555.

Cox, S. M., Cox, D. J., Kofler, M. J., Moncrief, M. A., Johnson, R. J., Lambert, A. E., ... Reeve, R. E. (2016). Driving simulator performance in novice drivers with autism spectrum disorder: The role of executive functions and basic motor skills. Journal of Autism and Developmental Disorders, 46(4), 1379-1391.

Cox, N. B., Reeve, R. E., Cox, S. M., \& Cox, D. J. (2012). Brief report: Driving and young adults with ASD: Parents' experiences. Journal of Autism and Developmental Disorders, 42(10), 2257-2262.

Crundall, D., Andrews, B., Van Loon, E., \& Chapman, P. (2010). Commentary training improves responsiveness to hazards in a driving simulator. Accident Analysis E Prevention, 42(6), 2117-2124.

Crundall, D., Chapman, P., Trawley, S., Collins, L., Van Loon, E., Andrews, B., \& Underwood, G. (2012). Some hazards are more attractive than others: Drivers of varying experience respond differently to different types of hazard. Accident Analysis E Prevention, 45, 600-609.

Crundall, D., \& Pradhan, A. K. (2016). Hazard avoidance in young novice drivers: definitions and a framework. In Handbook of teen and novice drivers (pp. 81-94). CRC Press.

Cuenen, A., Jongen, E. M., Brijs, T., Brijs, K., Lutin, M., Van Vlierden, K., \& Wets, G. (2016). The relations between specific measures of simulated driving ability and functional ability: New insights for assessment and training programs of older drivers. Transportation Research Part F: Traffic Psychology and Behaviour, 39, 65-78.

Curry, A. E., Yerys, B. E., Huang, P., \& Metzger, K. B. (2018). Longitudinal study of driver licensing rates among adolescents and young adults with autism spectrum disorder. Autism, 22(4), 479-488.

Daigneault, G., Joly, P., \& Frigon, J. Y. (2002). Executive functions in the evaluation of accident risk of older drivers. Journal of Clinical and Experimental Neuropsychology, 24(2), 221-238.

Daly, B. P., Nicholls, E. G., Patrick, K. E., Brinckman, D. D., \& Schultheis, M. T. (2014). Driving behaviors in adults with autism spectrum disorders. Journal of Autism and Developmental Disorders, 44(12), 3119-3128.

Edwards, J. D., Delahunt, P. B., \& Mahncke, H. W. (2009). Cognitive speed of processing training delays driving cessation. Journals of Gerontology Series A: Biomedical Sciences and Medical Sciences, 64(12), 1262-1267.

Edwards, J. D., Vance, D. E., Wadley, V. G., Cissell, G. M., Roenker, D. L., \& Ball, K. K. (2005). Reliability and validity of useful field of view test scores as administered by personal computer. Journal of Clinical and Experimental Neuropsychology, 27(5), 529-543.

Gardner, M., \& Steinberg, L. (2005). Peer influence on risk taking, risk preference, and risky decision making in adolescence and adulthood: An experimental study. Developmental Psychology, 41(4), 625-635.

Geurts, H. M., Verté, S., Oosterlaan, J., Roeyers, H., \& Sergeant, J. A. (2004). How specific are executive functioning deficits in attention deficit hyperactivity disorder and autism? Journal of Child Psychology and Psychiatry, 45(4), 836-854.

Gogtay, N., Giedd, J. N., Lusk, L., Hayashi, K. M., Greenstein, D., Vaituzis, A. C., ... Rapoport, J. L. (2004). Dynamic mapping of human cortical development during childhood through early adulthood. Proceedings of the National Academy of Sciences, 101(21), 8174-8179.

Gogtay, N., \& Thompson, P. M. (2010). Mapping gray matter development: Implications for typical development and vulnerability to psychopathology. Brain and Cognition, 72(1), 6-15.

Gugerty, L. (2011). Situation awareness in driving. In D. L. Fisher, M. Rizzo, J. Caird, \& J. D. Lee (Eds.), Handbook of driving simulation for engineering, medicine and psychology (pp. 265-272). CRC Press.

Hatfield, J., Williamson, A., Kehoe, E. J., \& Prabhakharan, P. (2017). An examination of the relationship between measures of impulsivity and risky simulated driving amongst young drivers. Accident Analysis and Prevention, 103, 37-43.

Hill, E. L. (2004). Evaluating the theory of executive dysfunction in autism. Developmental Review, 24, 189-233.

Hoofs, V., Princen, M. M., Poljac, E., Stolk, A., \& Poljac, E. (2018). Task switching in autism: An EEG study on intentions and actions. Neuropsychologia, 117, 398-407.

Houben, K., Wiers, R. W., \& Jansen, A. (2011). Getting a grip on drinking behavior: Training working memory to reduce alcohol abuse. Psychological Science, 22(7), 968-975.

Huang, P., Kao, T., Curry, A. E., \& Durbin, D. R. (2012). Factors associated with driving in teens with autism spectrum disorders. Journal of Developmental E Behavioral Pediatrics, 33(1), 70-74.

Hughes, C., Russell, J., \& Robbins, T. W. (1994). Evidence for executive dysfunction in autism. Neuropsychologia, 32(4), 477-492. 
Hull, L., Mandy, W., \& Petrides, K. V. (2017). Behavioural and cognitive sex/gender differences in autism spectrum condition and typically developing males and females. Autism, 21(6), 706-727.

Johnston, K., Madden, A. K., Bramham, J., \& Russell, A. J. (2011). Response inhibition in adults with autism spectrum disorder compared to attention deficit/ hyperactivity disorder. Journal of Autism and Developmental Disorders, 41(7), 903-912.

Jongen, E. M., Brijs, K., Komlos, M., Brijs, T., \& Wets, G. (2011). Inhibitory control and reward predict risky driving in young novice drivers - a simulator study. Procedia-Social and Behavioral Sciences, 20, 604-612.

Jongen, S., Perrier, J., Vuurman, E. F., Ramaekers, J. G., \& Vermeeren, A. (2015). Sensitivity and validity of psychometric tests for assessing driving impairment: Effects of sleep deprivation. PLoS One, 10(2) e0117045.

Klingberg, T., Forssberg, H., \& Westerberg, H. (2002). Increased brain activity in frontal and parietal cortex underlies the development of visuospatial working memory capacity during childhood. Journal of Cognitive Neuroscience, 14(1), 1-10.

Lambert, A. E., Simons-Morton, B. G., Cain, S. A., Weisz, S., \& Cox, D. J. (2014). Considerations of a dual-systems model of cognitive development and risky driving. Journal of Research on Adolescence, 24(3), 541-550.

Mäntylä, T., Karlsson, M. J., \& Marklund, M. (2009). Executive control functions in simulated driving. Applied Neuropsychology, 16(1), 11-18.

McCartt, A. T., Shabanova, V. I., \& Leaf, W. A. (2003). Driving experience, crashes and traffic citations of teenage beginning drivers. Accident Analysis E' Prevention, 35(3), 311-320.

McManus, B., Cox, M. K., Vance, D. E., \& Stavrinos, D. (2015). Predicting motor vehicle collisions in a driving simulator in young adults using the useful field of view assessment. Traffic injury Prevention, 16(8), 818-823.

Monahan, M., Classen, S., \& Helsel, P. V. (2013). Pre-driving evaluation of a teen with attention deficit hyperactivity disorder and autism spectrum disorder. Canadian Journal of Occupational Therapy, 80(1), 35-41.

Noens, I., De la Marche, W., \& Scholte, E. (2012). SRS-A-Screeningslijst voor autismespectrumstoornissen Handleiding. Amsterdam: Hogrefe.

Parsons, T. D., \& Carlew, A. R. (2016). Bimodal virtual reality stroop for assessing distractor inhibition in autism spectrum disorders. Journal of Autism and Developmental Disorders, 46(4), 1255-1267.

Patrick, K. E., Hurewitz, F., McCurdy, M. D., Agate, F. T., Daly, B. P., Tarazi, R. A., ... Schultheis, M. T. (2018). Driving comparisons between young adults with autism spectrum disorder and typical development. Journal of Developmental \& Behavioral Pediatrics, 39(6), 451-460.

Pellicano, E. (2012). The development of executive function in autism. Autism Research and Treatment.

Rajendran, G., Law, A. S., Logie, R. H., van der Meulen, M., Fraser, D., \& Corley, M. (2011). Investigating multitasking in high-functioning adolescents with autism spectrum disorders using the virtual errands task. Journal of Autism and Developmental Disorders, 41(11), 1445-1454. https://doi.org/10.1007/ s10803-010-1151-3.

Rapport, M. D., Orban, S. A., Kofler, M. J., \& Friedman, L. M. (2013). Do programs designed to train working memory, other executive functions, and attention benefit children with ADHD? A meta-analytic review of cognitive, academic, and behavioral outcomes. Clinical Psychology Review, 33(8), 1237-1252.

Reimer, B., Fried, R., Mehler, B., Joshi, G., Bolfek, A., Godfrey, K. M., ... Biederman, J. (2013). Brief report: Examining driving behavior in young adults with high functioning autism spectrum disorders: A pilot study using a driving simulation paradigm. Journal of Autism and Developmental Disorders, 43(9), $2211-2217$.

Ross, V., Cox, D. J., Reeve, R., Brown, T., Moncrief, M., Schmitt, R., \& Gaffney, G. (2018). Measuring the attitudes of novice drivers with autism spectrum disorder as an indication of apprehensive driving: Going beyond basic abilities. Autism, 22(1), 62-69.

Ross, V., Jongen, E. M., Brijs, K., Vanroelen, G., Maltagliati, I., Brijs, T., ... \& Vanvuchelen, M. (2017). The reaction to hazards in young novice drivers with an autism spectrum disorder: a driving simulator study. In Proceedings of the 7th International Road Safety and Simulation.

Ross, V., Jongen, E. M., Brijs, K., Brijs, T., \& Wets, G. (2016). Investigating risky, distracting, and protective peer passenger effects in a dual process framework. Accident Analysis \& Prevention, 93, 217-225.

Ross, V., Jongen, E., Brijs, T., Ruiter, R., Brijs, K., \& Wets, G. (2015). The relation between cognitive control and risky driving in young novice drivers. Applied Neuropsychology: Adult, 22(1), 61-72.

Ross, V., Jongen, E., Vanvuchelen, M., Brijs, T., Brijs, K., \& Wets, G. (2015). Exploring the driving behavior of youth with an autism spectrum disorder: A driver instructor questionnaire. Proceedings of the 8th driving symposium on human factors in driver assessment, training and vehicle design. UT: Salt Lake City.

Ross, V., Jongen, E. M., Wang, W., Brijs, T., Brijs, K., Ruiter, R. A., \& Wets, G. (2014). Investigating the influence of working memory capacity when driving behavior is combined with cognitive load: An LCT study of young novice drivers. Accident Analysis E Prevention, 62, 377-387.

Sagberg, F., \& Bjørnskau, T. (2006). Hazard perception and driving experience among novice drivers. Accident Analysis E’ Prevention, 38(2), 407-414.

Sekuler, R., \& Ball, K. (1986). Visual localization: Age and practice. JOSA A, 3(6), 864-867.

Sheppard, E., Ropar, D., Underwood, G., \& van Loon, E. (2010). Brief report: Driving hazard perception in autism. Journal of Autism and Developmental Disorders, 40, 504-508.

Sheppard, E., Van Loon, E., Underwood, G., \& Ropar, D. (2017). Attentional differences in a driving hazard perception task in adults with autism spectrum disorders. Journal of Autism and Developmental Disorders, 47(2), 405-414.

Sinzig, J., Morsch, D., Bruning, N., Schmidt, M. H., \& Lehmkuhl, G. (2008). Inhibition, flexibility, working memory and planning in autism spectrum disorders with and without comorbid ADHD-symptoms. Child and Adolescent Psychiatry and Mental Health, 2(1), 4.

Solomon, M., Ozonoff, S. J., Ursu, S., Ravizza, S., Cummings, N., Ly, S., \& Carter, C. S. (2009). The neural substrates of cognitive control deficits in autism spectrum disorders. Neuropsychologia, 47(12), 2515-2526.

Stanton, N. A., \& Salmon, P. M. (2009). Human error taxonomies applied to driving: A generic driver error taxonomy and its implications for intelligent transport systems. Safety Science, 47(2), 227-237.

Starkey, N. J., \& Isler, R. B. (2016). The role of executive function, personality and attitudes to risks in explaining self-reported driving behaviour in adolescent and adult male drivers. Transportation Research Part F: Traffic Psychology and Behaviour, 38, 127-136.

Steinberg, L. (2005). Cognitive and affective development in adolescence. Trends in Cognitive Sciences, 9, 69-74.

Steinberg, L. (2008). A social neuroscience perspective on adolescent risk-taking. Developmental review, 28(1), 78-106.

Stevens, M. C., Kiehl, K. A., Pearlson, G. D., \& Calhoun, V. D. (2007). Functional neural networks underlying response inhibition in adolescents and adults. Behavioural Brain Research, 181(1), 12-22.

Turner, M. A. (1999). Generating novel ideas: Fluency performance in high-functioning and learning disabled individuals with autism. The Journal of Child Psychology and Psychiatry and Allied Disciplines, 40(2), 189-201.

Van Eylen, L., Boets, B., Steyaert, J., Evers, K., Wagemans, J., \& Noens, I. (2011). Cognitive flexibility in autism spectrum disorder: Explaining the inconsistencies? Research in Autism Spectrum Disorders, 5(4), 1390-1401.

Verbruggen, F., \& Logan, G. D. (2008). Response inhibition in the stop-signal paradigm. Trends in Cognitive Sciences, 12, $418-424$.

Vermeulen, P. (2015). Context blindness in autism spectrum disorder: Not using the forest to see the trees as trees. Focus on Autism and Other Developmental Disabilities, 30(3), 182-192.

Vermeulen, P. (2009). Autisme als contextblindheid (1e druk), Epo Uitgeverij. ISBN 9789064455476

Verte, S., Geurts, H. M., Roeyers, H., Oosterlaan, J., \& Sergeant, J. A. (2005). Executive functioning in children with autism and Tourette syndrome. Development and Psychopathology, 17(2), 415-445.

Wade, J., Weitlauf, A., Broderick, N., Swanson, A., Zhang, L., Bian, D., ... Sarkar, N. (2017). A pilot study assessing performance and visual attention of teenagers with ASD in a novel adaptive driving simulator. Journal of Autism and Developmental Disorders, 47(11), 3405-3417.

Walshe, E., Ward McIntosh, C., Romer, D., \& Winston, F. (2017). Executive function capacities, negative driving behavior and crashes in young drivers. International journal of environmental research and public health, 14(11), 1314.

Wang, W., Jongen, E. M. M., Brijs, K., Brijs, T., Ruiter, R. A. C., \& Wets, G. (2013). Linking the visual search skills of safe driving to executive functions among young novice drivers. In European conference on eye movements. Lund, Sweden. 
White, E. I., Wallace, G. L., Bascom, J., Armour, A. C., Register-Brown, K., Popal, H. S., ... Kenworthy, L. (2017). Sex differences in parent-reported executive functioning and adaptive behavior in children and young adults with autism spectrum disorder. Autism Research, 10(10), 1653-1662.

Woutersen, K., Guadron, L., van den Berg, A. V., Boonstra, F. N., Theelen, T., \& Goossens, J. (2017). A meta-analysis of perceptual and cognitive functions involved in useful-field-of-view test performance. Journal of Vision, 17(14), 11.

Xiao, T., Xiao, Z., Ke, X., Hong, S., Yang, H., Su, Y., ... Liu, Y. (2012). Response inhibition impairment in high functioning autism and attention deficit hyperactivity disorder: Evidence from near-infrared spectroscopy data. PLoS ONE, 7, e46569. 